\title{
Focus on the brain and systemic organ systems: when essential interactions become toxic relationships
}

\author{
M. Smith ${ }^{1^{*}}$ (D) and G. Meyfroidt ${ }^{2,3}$
}

๑) 2018 Springer-Verlag GmbH Germany, part of Springer Nature and ESICM

Acute brain injury outcomes are driven not only by the underlying neurologic pathology but also by non-neurological (systemic) complications [1]. Conversely, systemic illness as the primary process can have deleterious effects on the brain [1, 2] (Fig. 1). Cross-talk between brain and systemic organ systems is a well-known mechanism [3, 4], but the impact of treatment on these interactions is equally important. For example, while status epilepticus (SE) may lead to permanent neuronal injury and catecholamine-related systemic complications, its treatment may also affect morbidity and mortality. Despite aggressive first-line (benzodiazepines) and second-line (phenytoin/ fosphenytoin, levetiracetam) interventions, more than $40 \%$ of these patients will progress to refractory SE [5]. This requires treatment with general anesthetics which may lead to systemic complications, including hypotension requiring vasopressors, immunosuppression and ileus. An algorithmic approach to the management of refractory SE designed to rapidly terminate seizures while minimizing the risk of both neurologic and systemic complications has recently been described [5].

The brain interacts with the heart and lungs via a complex interplay between humoral, neural and cellular pathways $[3,4]$. Acute lung injury (ALI) develops in more than $20 \%$ of traumatic brain injury (TBI) patients and increases their in-hospital mortality [6]. In experimental models, TBI increases the vulnerability of the lungs to mechanical injury and also to non-mechanical

\footnotetext{
${ }^{*}$ Correspondence: martin.smith@ucl.ac.uk

${ }^{1}$ Neurocritical Care Unit, The National Hospital for Neurology and Neurosurgery, University College London Hospitals, Queen Square, London, UK

Full author information is available at the end of the article
}

injury such as inflammation or ischemia-reperfusion [7]. In patients with previously normal neurologic function, primary ALI can lead to brain damage through release of inflammatory mediators following stimulation of mechanical and chemical receptors in the lungs, airway and respiratory muscles [3]. Importantly, even in healthy lungs, mechanical ventilation (MV) can cause or worsen brain injury secondary to a deleterious inflammatory response. While lung-protective ventilation strategies might mitigate these adverse effects, they may conflict with recommended therapeutic targets for brain-injured patients. For example, permissive hypercarbia might not be appropriate because even modest increases in $\mathrm{PaCO}_{2}$ can result in intractable rises in intracranial pressure if brain compliance is reduced. Conversely, protective MV could be beneficial for pulmonary and neurological outcomes by reducing the inflammation associated with ventilator-induced lung injury [8]. However, the outcome benefits of implementing respiratory care bundles in TBI patients remain unclear in the absence of large randomized controlled trials [9]. In the French BIVILI project, a multi-faceted approach combining lungprotective ventilation and an early extubation strategy in brain-injured patients was implemented in 20 ICU's [10]. Using a prospective before-after study design, a benefit of ventilator-free days and 90-day mortality could not be demonstrated, but overall compliance with the ventilation care bundle was low. Of note, the small subgroup of patients whose care complied with the entire set of bundle recommendations did have better 90-day outcomes and a higher number of ventilator-free days.

Brain-heart interconnections have been recognized for decades [4]. Neurocardiogenic injury is associated with increased all-cause and cardiac mortality after

\section{Springer}




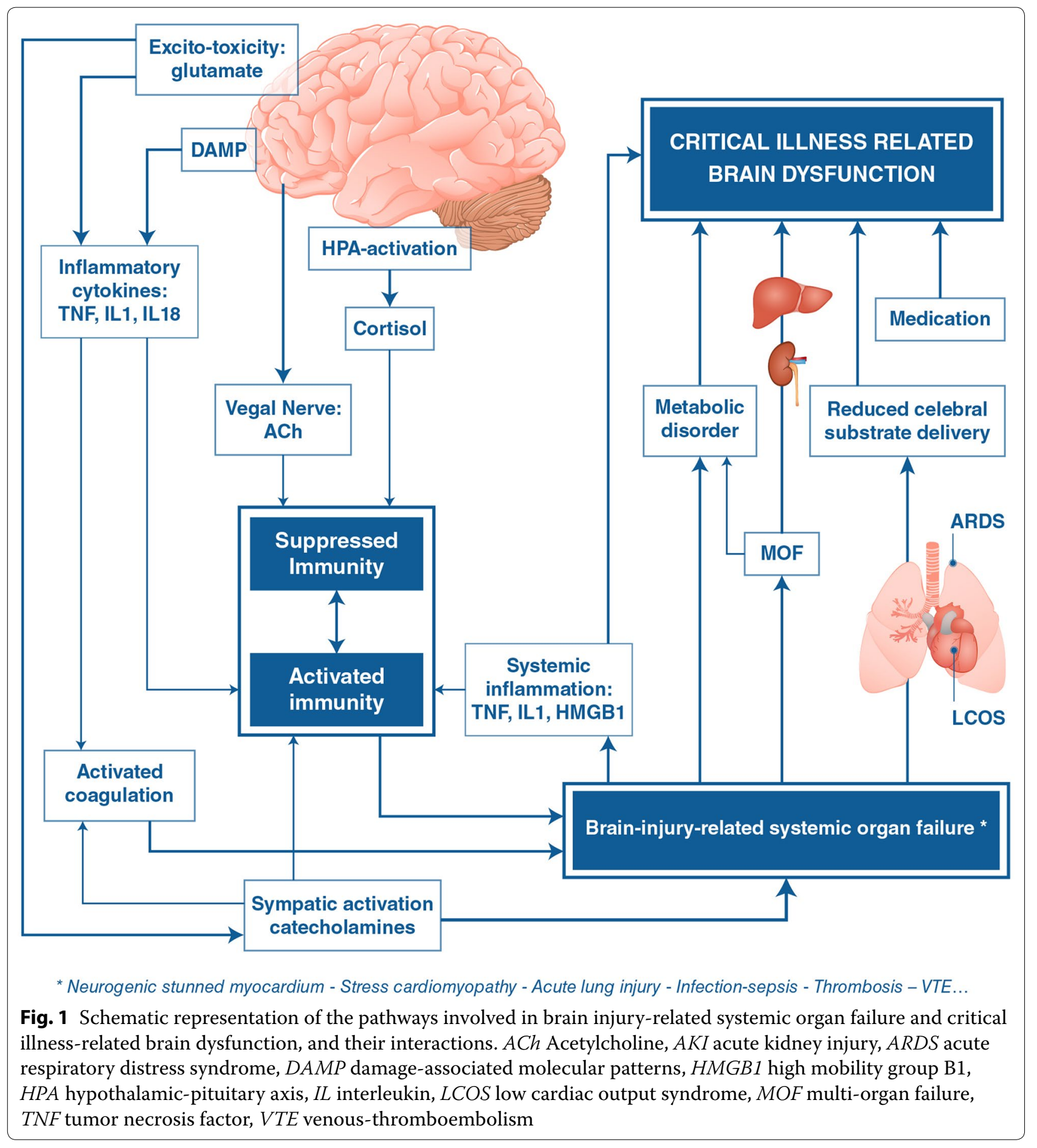

subarachnoid hemorrhage [11]. Like for the lungs, primary cardiac injury can also adversely impact the normal brain [12]. Brain injury-related cardiac complications (neurogenic stunned myocardium and stress cardiomyopathy) are often temporary and reversible, so treatment is generally focused on supportive care and management of the underlying brain injury [11]. However, optimal management strategies for failing systemic organ systems, including blood pressure, fluid balance, blood gas and hemoglobin targets, can conflict with what is recommended in brain-injured patients. 
Neurologic disease, and particularly TBI, is a risk factor for venous thromboembolism (VTE). Both physical and pharmacological (low-molecular-weight heparin or lowdose unfractionated heparin) prophylaxis methods are recommended. Pharmacological VTE prophylaxis should be started after $48 \mathrm{~h}$ in those at low risk of hematoma expansion and after $72 \mathrm{~h}$ in patients at medium or high risk, based on evidence from over 5000 TBI patients [13]. However, a post hoc analysis of 603 patients in the erythropoietin in TBI trial demonstrated that such practice is not widespread [14]. While the early use of mechanical prophylaxis was almost universal in this study (91\% of patients on day 1 and $97 \%$ by day 3), pharmacological prophylaxis was delayed until day 3 in 30\% of patients and had been implemented in only $57 \%$ by day 7 . Onethird of VTE events (in almost $20 \%$ of patients) developed within the first 3 days, but the impact of the delay in chemoprophylaxis on this finding is unclear. Risk factors for VTE included worse TBI severity, highlighting the need for further studies in this high-risk group.

The impact of general critical illness on the brain can be substantial. Sepsis is frequently complicated by encephalopathy, which is associated with worse short- and longterm outcomes, including permanent cognitive and other neurologic impairments [2]. A recent retrospective analysis of a prospective, multi-center database including 2513 patients with sepsis at ICU admission, demonstrated that even mild alterations in mental status (GCS of 13-14) were independently associated with mortality [15]. Overall, the development of encephalopathy was associated with higher use of ICU resources, longer hospital stay, and higher mortality. Acute renal failure, hypo- as well as hyperglycemia, hypercapnea, hypernatremia and $S$. aureus infection were independent risk factors for sepsisrelated encephalopathy. Although a causal relationship could not be proven in this observational trial, these risk factors are potentially modifiable.

In summary, the critical care management of acute brain injury should take into account the complex interactions between the brain and systemic organ systems. On the other hand, the potential for systemic illness to cause acute brain dysfunction is ever present, and strategies that protect the brain as well as systemic organ systems should be incorporated into general critical care management. In some situations, therapeutic dilemmas or double-edged sword choices cannot be avoided. Therapy may then be a compromise on an individual basis, balancing the potential for adverse effects on the injured brain of treatment for failing systemic organ systems, and vice versa. While the epidemiology and mechanisms of these complex brain-systemic inter-relationships are increasingly understood, well-designed studies investigating therapeutic approaches to recognize and manage systemic complications in primary brain injury, or brainoriented interventions in general critical care patients, are crucial to improve clinical outcomes [1].

\begin{abstract}
Author details
${ }^{1}$ Neurocritical Care Unit, The National Hospital for Neurology and Neurosurgery, University College London Hospitals, Queen Square, London, UK. ${ }^{2}$ Department of Intensive Care Medicine, University Hospitals Leuven, Leuven, Belgium. ${ }^{3}$ Laboratory of Intensive Care Medicine, KU Leuven, Herestraat 49, 3000 Leuven, Belgium.
\end{abstract}

\section{Compliance with ethical standards}

\section{Conflicts of interest}

MS is Editor in Chief of the Journal of Neurosurgical Anesthesiology. The authors have no other conflicts of interest to declare.

Received: 14 September 2018 Accepted: 26 October 2018

Published online: 5 November 2018

\section{References}

1. Bleck TP (2018) How critical illness affects the brain ... and vice versa. Crit Care Med 46:465-470

2. Smith M, Meyfroidt G (2017) Critical illness: the brain is always in the line of fire. Intensive Care Med 43:870-873

3. Blanch L, Quintel M (2017) Lung-brain cross talk in the critically ill. Intensive Care Med 43:557-559

4. Mazzeo AT, Micalizzi A, Mascia L, Scicolone A, Siracusano L (2014) Brain-heart crosstalk: the many faces of stress-related cardiomyopathy syndromes in anaesthesia and intensive care. Br J Anaesth 112:803-815

5. Legriel S, Oddo M, Brophy GM (2017) What's new in refractory status epilepticus? Intensive Care Med 43:543-546

6. Rincon F, Ghosh S, Dey S, Maltenfort M, Vibbert M, Urtecho J, McBride W, Moussouttas M, Bell R, Ratliff JK, Jallo J (2012) Impact of acute lung injury and acute respiratory distress syndrome after traumatic brain injury in the United States. Neurosurgery 71:795-803

7. Lopez-Aguilar J, Villagra A, Bernabe F, Murias G, Piacentini E, Real J, Fernandez-Segoviano P, Romero PV, Hotchkiss JR, Blanch L (2005) Massive brain injury enhances lung damage in an isolated lung model of ventilator-induced lung injury. Crit Care Med 33:1077-1083

8. Mazzeo AT, Fanelli V, Mascia L (2013) Brain-lung crosstalk in critical care: how protective mechanical ventilation can affect the brain homeostasis. Minerva Anestesiol 79:299-309

9. Asehnoune K, Balogh Z, Citerio G, Cap A, Billiar T, Stocchetti N, Cohen MJ, Pelosi P, Curry N, Gaarder C, Gruen R, Holcomb J, Hunt BJ, Juffermans NP, Maegele M, Midwinter M, Moore FA, O'Dwyer M, Pittet JF, Schochl H, Schreiber M, Spinella PC, Stanworth S, Winfield R, Brohi K (2017) The research agenda for trauma critical care. Intensive Care Med 43:1340-1351

10. Asehnoune K, Mrozek S, Perrigault PF, Seguin P, Dahyot-Fizelier C, Lasocki S, Pujol A, Martin M, Chabanne R, Muller L, Hanouz JL, Hammad E, Rozec B, Kerforne T, Ichai C, Cinotti R, Geeraerts T, Elaroussi D, Pelosi P, Jaber S, Dalichampt M, Feuillet F, Sebille V, Roquilly A (2017) A multi-faceted strategy to reduce ventilation-associated mortality in brain-injured patients. The BI-VILI project: a nationwide quality improvement project. Intensive Care Med 43:957-970

11. Van der Bilt IAC, Hasan D, Vandertop WP, Wilde AA, Algra A, Visser FC, Rinkel GJ (2009) Impact of cardiac complications on outcome after aneurysmal subarachnoid hemorrhage: a meta-analysis. Neurology 72:635-642

12. Havakuk O, King KS, Grazette L, Yoon AJ, Fong M, Bregman N, Elkayam U, Kloner RA (2017) Heart failure-induced brain injury. J Am Coll Cardiol 69:1609-1616

13. Abdel-Aziz H, Dunham CM, Malik RJ, Hileman BM (2015) Timing for deep vein thrombosis chemoprophylaxis in traumatic brain injury: an evidence-based review. Crit Care 19:96 
14. Skrifvars MB, Bailey M, Presneill J, French C, Nichol A, Little L, Duranteau J, Huet O, Haddad S, Arabi Y, MCArthur C, Cooper DJ, Bellomo R (2017) Venous thromboembolic events in critically ill traumatic brain injury patients. Intensive Care Med 43:419-428

15. Sonneville R, de Montmollin E, Poujade J, Garrouste-Orgeas M, Souweine B, Darmon M, Mariotte E, Argaud L, Barbier F, Goldgran-Toledano D,
Marcotte G, Dumenil AS, Jamali S, Lacave G, Ruckly S, Mourvillier B, Timsit JF (2017) Potentially modifiable factors contributing to sepsis-associated encephalopathy. Intensive Care Med 43:1075-1084 